\title{
Systematic approach for improving energy efficiency in industrial facilities, from energy audit to practical implementation - case study production of autoclaved aerated concrete
}

\author{
Boris Sucic ${ }^{1, *}$, Marko Peckaj ${ }^{1}$, Zeljko Tomsic ${ }^{2}$, and Jani Uranic ${ }^{3}$ \\ ${ }^{1}$ Jožef Stefan Institute, Energy Efficiency Centre, SI-1000 Ljubljana, Slovenia \\ ${ }^{2}$ Univercity of Zagreb, Faculty of Electrical Engineering and Computing, HR-10000 Zagreb \\ ${ }^{3}$ Xella Porobeton Si d.o.o., SI-1412 Kisovec, Slovenia
}

\begin{abstract}
In today's globalized world, need for competitiveness on one side and constant pressure on the reduction of negative environmental impacts on the other side, are forcing industrial companies to systematically analyse all possibilities for the optimization of their production processes. This paper presents a systematic approach for improving energy efficiency in industrial facilities. Special attention was given to activities that were necessary for the proper identification of energy saving potential and implementation of selected energy efficiency measures in the complex industrial environment. The proposed approach includes four main activities: (1) energy auditing, identification and valorisation of opportunities for improving energy efficiency, (2) identification of key personnel who needs to be trained and motivated to become involved and to make energy efficient decisions in practice, (3) implementation of selected energy efficiency measures and (4) continuous monitoring and verification of achieved results. The proposed approach has been tested in the real industrial environment and the results are confirming that significant energy savings and overall improvement of competitiveness can be reached. Additionally, special emphasis was placed on soft elements like cooperation between energy experts, process operators and maintenance staff that are crucial for the overall success.
\end{abstract}

\section{Introduction}

The main targets of 2030 climate and energy framework of European Union (EU) are decreasing the greenhouse gas emissions by at least $40 \%$ below 1990 levels, improving the energy efficiency up to $32.5 \%$ and increasing share of the renewable energy sources (RES) up to $32 \%$ of final energy consumption. According to European Environment Agency [1], between 2005 and 2016 final energy consumption in industry decreased by $16.4 \%$ in the EU28 due to improved economic performance, implemented structural changes,

*Corresponding author: boris.sucic@ijs.si 
improvements in end-use efficiency and lower heat consumption due to favourable climatic conditions. On the other hand, it has to be aware that due to higher economic activity between 2015 and 2016, the total final energy consumption in the EU28 increased by $2 \%$ above its 2020 target [1]. In this context European industry has an important role and it is expected that the industry will enable and provide new technologies for transition towards low carbon economy without jeopardizing its competitiveness. However, it is not the first time that many countries have defined challenging energy and climate related long-term objectives but lack of clear definition of responsibilities with deadlines for the implementation of proposed measures was the crucial reason why many goals have not been achieved [2]. Additionally, according to [3], different business contexts have a different potential for the energy efficiency transformation of enterprises underlining that enterprises in EU countries with more stringent regulations have been shown to be significantly more likely to undertake and implement comprehensive energy efficiency programs. According to [4], significant improvements in energy efficiency may require sophisticated measurement, analysis and control techniques. Also, analysis performed by Arens and Worrell [5] clearly shows that there is still room for further implementation of the energy efficient technologies in energy intensive industries even in technologically advanced countries like Germany where the industrial energy efficiency transformation has started over 30 years ago. Specific measures that have been shown to work well include efficiency targets and standards, benchmarking, energy audits and energy management requirements, complemented by training, capacity-building, information provision and awareness raising campaigns [5]. The similar situation is also in Slovenian industry and providing a suitable environment for its further development which should be based on energy and resource efficiency, is of key importance for improving the overall national competitiveness and at the same time achieving common EU climate and energy goals [6].

According to [7], energy audits and energy management systems are recognized as important instruments to improve energy efficiency in industry. Similar findings in many other research studies were also recognised by the European Commission in its Energy Efficiency Directive and formalized by introducing Article 8 which has made regular energy audits an obligation for large companies [8]. Unfortunately, research work presented by Nabitz and Hirzel [9] clearly revealed that concrete requirements and recommendations how to conduct an energy audit significantly differ across Member States. A common mistake of energy and environmental auditing is that the adopted approach is too narrow and the focus is only on the utility side, specific technical solutions or computerized control [10]. Research work presented by Lazzarin and Noro [11] besides comprehensive overview of energy efficiency opportunities in the production process of cast iron foundries, also included detailed description of energy audit process. According to [12], there is a need for establishing a novel approach combining the total site, cleaner production and energy efficiency optimisation techniques to increase energy efficiency based on versatile industrial practices. Boldyryev et al. [13] clearly demonstrated potentials of heat recovery in the cement production by using the process integration approach. Process integration is a family of methodologies for combining several processes to reduce consumption of energy and raw materials, and to reduce negative environmental impacts. Due to its simplicity and results obtained in many applications around the world, the pinch analysis is the most widely used process integration methodology [14-16]. Having in mind potentials of digitalisation in industry, D'Aniello et al. [17] proposed innovative energy performance metrics for high-level monitoring and diagnosis of telecommunication sites which after successful adaptation can be used for advanced monitoring of the efficiency of thermal management strategies of any data room in different industrial branches. Research work presented by Savulescu et al. [18] provided novel approach including innovative 
visualization technique for energy flow analysis with the emphasis on energy and waste heat mapping.

This paper presents a systematic approach for improving energy efficiency in industrial facilities. Special attention was given to activities that were necessary for the proper identification of energy saving potential and implementation of selected energy efficiency measures in the complex industrial environment. The proposed approach aims at supporting energy experts in industrial companies in optimizing energy performance of both supply and demand side aspect of their work and it is based on four main activities: (1) energy auditing, identification and valorisation of opportunities for improving energy efficiency, (2) identification of key personnel who needs to be trained and motivated to become involved and to make energy efficient decisions in practice, (3) implementation of selected energy efficiency measures and (4) continuous monitoring and verification of achieved results. The proposed approach has been tested in the real industrial environment and the special emphasis was placed on soft elements like cooperation between energy experts, process operators and maintenance staff that proved to be crucial for reaching set targets.

\section{Methodology}

The overall idea behind proposed approach for improving energy efficiency in industrial facilities is based on a comprehensive set of activities that has to be conducted in systematic manner and must include metering, monitoring and evaluation of energy and environmental performance. Identified activities and actors involved in the implementation of the proposed approach for improving energy efficiency in industrial facilities are presented in Table 1.

Based on presented activities it is clear that the energy manager and his team are placed in the centre of the proposed approach. In this sense the energy manager is a person who evaluates energy use, designs and then supervises the implementation of energy efficiency measures. According to [19], in the real industrial environment energy managers are responsible for closing the gap between theory and practice and to provide the necessary background and help for decision makers when they are dealing with energy-related issues. Also, for the overall success of the proposed approach and for reaching sustainable energy savings, support and honest cooperation between energy manager and external experts during energy audit is vitally important. In this context energy audit must provide information about potential equipment and technology improvements but also information about personnel that significantly affects consumption of energy and raw materials. During the energy audit their motivational and training needs must be properly addressed. Another important step of the proposed approach is connected with the implementation of energy management system and setting a baseline for the performance monitoring. One of the basic assumptions of the proposed approach is that the monitored energy consumption and properly defined baseline for performance monitoring can be the basis for the identification of energy profiles as well as energy and resource efficiency improvements. Insufficient or inappropriate monitoring of energy consumption may hinder the companies' potential by not capitalizing fully on their energy investments [20]. Additionally, energy management system with performance monitoring capabilities is a vital element for the verification of achieved energy savings. Definition of proper set of key performance indicators is just one part of initial equation. The second and equally important part of the equation is connection of proposed set of key performance indicators with the skilled and motivated employees who will react on notification about abnormalities in energy and resource efficiency. During the design of the action plan for the implementation of priority measures additional care has to be dedicated to the evaluation of potential interlinks and impacts between 
proposed measures. For example, reduction of operating hours of electrical lighting system (good housekeeping measure - turn off the lighting system when you do not need it) has an important impact on the feasibility of the energy efficiency measure involving replacement of old and inefficient lamps with new and efficient units.

Table 1. Identified activities and actors involved in the systematic approach for improving energy efficiency in industrial facilities.

\begin{tabular}{|c|c|}
\hline Activity & Actor involved \\
\hline Appointment of Energy Manager & Top management \\
\hline $\begin{array}{l}\text { Self-assessment of the energy needs and } \\
\text { operational practices }\end{array}$ & Energy manager \\
\hline $\begin{array}{l}\text { Energy audit - external evaluation of current } \\
\text { operational practices and performance }\end{array}$ & $\begin{array}{l}\text { Independent external expert organisation } \\
\text { supported by energy manager }\end{array}$ \\
\hline $\begin{array}{l}\text { Additional education and training for energy } \\
\text { manager }\end{array}$ & $\begin{array}{l}\text { Energy manager with the formal approval } \\
\text { from top management }\end{array}$ \\
\hline $\begin{array}{l}\text { Proposal of the energy efficiency strategy and } \\
\text { action plan for the implementation of priority } \\
\text { measures }\end{array}$ & $\begin{array}{l}\text { Independent external expert organisation with } \\
\text { the support of energy manager }\end{array}$ \\
\hline $\begin{array}{l}\text { Adoption of the energy efficiency strategy } \\
\text { and action plan for the implementation of } \\
\text { priority measures }\end{array}$ & Top management \\
\hline $\begin{array}{l}\text { Implementation of Energy Management } \\
\text { System and setting a baseline for the } \\
\text { performance monitoring }\end{array}$ & $\begin{array}{l}\text { Energy manager supported by independent } \\
\text { external expert organisation and head of } \\
\text { technology and production }\end{array}$ \\
\hline $\begin{array}{l}\text { Advanced training activities for energy } \\
\text { manager }\end{array}$ & $\begin{array}{c}\text { Energy manager (approved by top } \\
\text { management) }\end{array}$ \\
\hline $\begin{array}{l}\text { Definition of initial targets for performance } \\
\text { monitoring - key performance indicators }\end{array}$ & $\begin{array}{l}\text { Energy manager in close cooperation with } \\
\text { head of technology and production }\end{array}$ \\
\hline $\begin{array}{l}\text { Establishment of team for energy efficiency at } \\
\text { the shop floor level - assigning } \\
\text { responsibilities to selected team of employees }\end{array}$ & Energy manager \\
\hline $\begin{array}{l}\text { Implementation of selected energy efficiency } \\
\text { projects }\end{array}$ & $\begin{array}{l}\text { Companies specialised for electrical, } \\
\text { mechanical and construction works } \\
\text { supervised by energy manager and his team }\end{array}$ \\
\hline Verification of performance improvements & Energy manager \\
\hline Implementation of potential corrective actions & $\begin{array}{c}\text { Energy manager in close cooperation with } \\
\text { head of technology and production }\end{array}$ \\
\hline Learning, continuity and communication & $\begin{array}{l}\text { Energy manager with the support of } \\
\text { independent external expert organisation }\end{array}$ \\
\hline $\begin{array}{l}\text { Adaptation and redefinition of energy } \\
\text { efficiency strategy, energy auditing, } \\
\text { redefinition of targets for performance } \\
\text { monitoring and setting a new baseline - } \\
\text { continuous process }\end{array}$ & $\begin{array}{c}\text { Energy manager in close cooperation with } \\
\text { head of technology and production and with } \\
\text { the support of independent external expert } \\
\text { organisation }\end{array}$ \\
\hline
\end{tabular}

\section{Results and discussion - case study producer of autoclaved aerated concrete in Slovenia}

Proposed approach for improving energy efficiency in industrial facilities has been tested on a case study of a producer of autoclaved aerated concrete in Slovenia. Addressed company is situated in central Slovenia and it has been producing products of autoclaved 
aerated concrete 1977 . Since 2004 it is a part of international company with a rich industrial tradition and knowledge in producing building materials, dry lining panels and lime and limestone products. During the financial and economic crisis yearly production was significantly reduced to around 75 thousand cubic meters of aerated concrete, primarily used on Slovene and partly on Croatian market. Beside the cement, which is the main raw material, sand, lime, gypsum, aluminium powder, returned sludge and water are also used in the production of autoclaved aerated concrete. Around $85 \%$ of company's energy needs are covered by natural gas which is used for the production of steam and for heating. Electricity is used for the various machinery (mills, mixers, pumps and ventilation system), production of compressed air, electrical lighting, office equipment and control systems.

Constant need for competitiveness on the market and changes in construction sector are forcing addressed company to systematically and continuously analyse all possibilities for the optimization of production activities and related costs reduction. At the beginning of the transformation process an energy manager was appointed and an energy audit with the support of external expert organisation was done. From the very beginning energy manager cooperated closely with the team of external experts and successfully guided and supervised all activities during the energy audit. During the energy audit comprehensive set of measurements was done and important equipment, processes and activities that characterise both energy and water consumption were recognised. Energy audit revealed several weak points regarding energy and resource efficiency and the following energy efficiency measures were proposed:

- Implementation of energy management system,

- Selection of appropriate tariff system and peak load management,

- Process integration and waste heat utilisation,

- Rehabilitation of the steam system and reduction of leakages,

- Rehabilitation of the compressed air system and reduction of leakages,

- Replacement of old and inefficient compressor with new variable speed drive compressor,

- Renovation of electrical lighting system.

The guiding principle for implementation of energy management system was to follow the activities, organisation structure and energy flows at the location. To cover energy and water consumption in a systematic manner, it was necessary to establish new metering infrastructure together with the new communication equipment for data acquisition. New metering infrastructure provided the framework for performance monitoring and targeting at each designated responsibility centre and directly connected people with tasks in the respected processes. At the beginning 21 metering devices were installed throughout the factory and included in energy management system. All identified energy saving measures have been implemented and the summary of achievements is presented in Table 2 .

The main energy savings were related with the process integration and waste heat utilisation which is similar with findings and recommendations reported by Friedler [14], Klemeš and Lam [15] and Chew et al [16]. Regarding the electricity consumption special attention was given to the compressed air system. Unfortunately, initial expectations were confirmed by measurements which were indicating that specific energy consumption for compress air production was around $0.168 \mathrm{kWh} / \mathrm{Nm}^{3}$, while modern compress air systems have specific energy consumption between 0.09 and $0.11 \mathrm{kWh} / \mathrm{Nm}^{3}$. During the evaluation process many different options were analysed but at the end it was decided that replacement of the auxiliary compressor with a new variable speed drive compressor should be the optimal solution. During the preliminary evaluation many leakages were detected in the 
system and air leak losses were estimated on $46 \%$ of total annual compressed air production. Monitoring and verification of energy savings due to installation of new variable speed drive compressor in the addressed plant is given in Figure 1.

Table 2. Summary of energy efficiency achievements in the addressed industrial plant.

\begin{tabular}{|c|c|}
\hline $\begin{array}{c}\text { Achieved and verified energy and water } \\
\text { saving potential }\end{array}$ & $\begin{array}{c}591,200 \mathrm{kWh} / \text { year \& } 350 \mathrm{~kW} / \text { month (electricity) } \\
2,664,000 \mathrm{kWh} / \text { year (natural gas) } \\
5,000 \mathrm{~m}^{3} / \text { year (water),Top management }\end{array}$ \\
\hline Total achieved cost reduction & $230,300 \mathrm{EUR} /$ year \\
\hline Reduction of $\mathrm{CO}_{2}$ emissions & $837 \mathrm{t} / \mathrm{year}$ \\
\hline Total investment costs & $177,500 \mathrm{EUR}$ \\
\hline Overall payback period (static) & 0.8 years \\
\hline
\end{tabular}

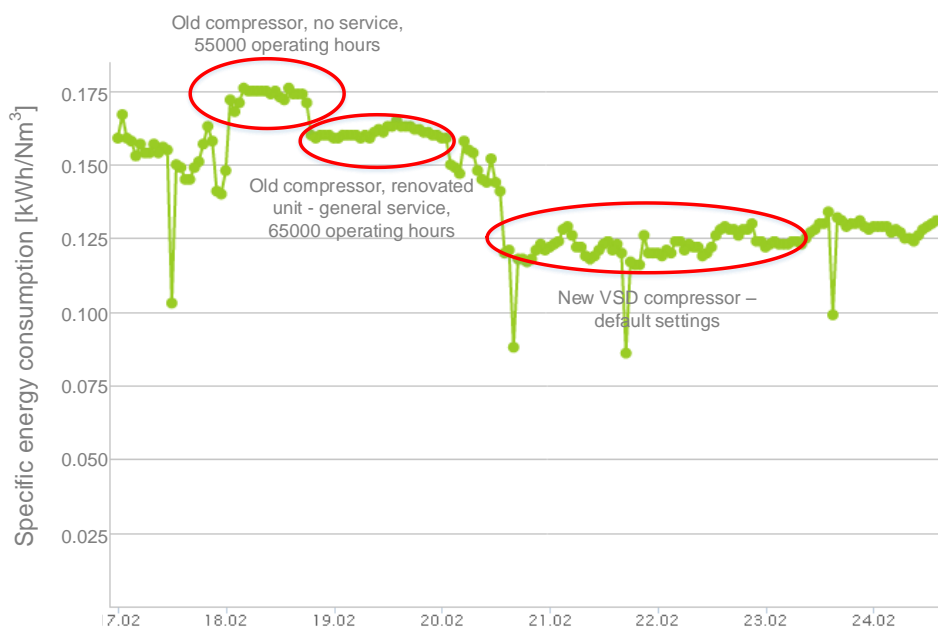

Fig. 1. Monitoring and verification of energy savings due to installation of new variable speed drive compressor in the addressed plant.

To reach the initial objective (specific energy consumption between 0.09 and $0.11 \mathrm{kWh} / \mathrm{Nm}^{3}$ ) it was not enough just to replace the old compressor, which has brought a $30 \%$ reduction in specific energy consumption, but it was also necessary to change several operating procedures to fine tune the operation of entire system and to establish effective performance monitoring and alarming system. At the end and with the extra efforts of energy manager and his team, set target has been reached and the company is maintaining its specific energy consumption in the compressed air system at the level of $0.108 \mathrm{kWh} / \mathrm{Nm}^{3}$.

All implemented measures resulted in significant improvement of specific energy consumption per unit of produced autoclaved aerated concrete. Evolution of specific energy consumption in addressed plant from 2003 up to 2016 and comparison with other plants belonging to the same group is presented in Figure 2. 


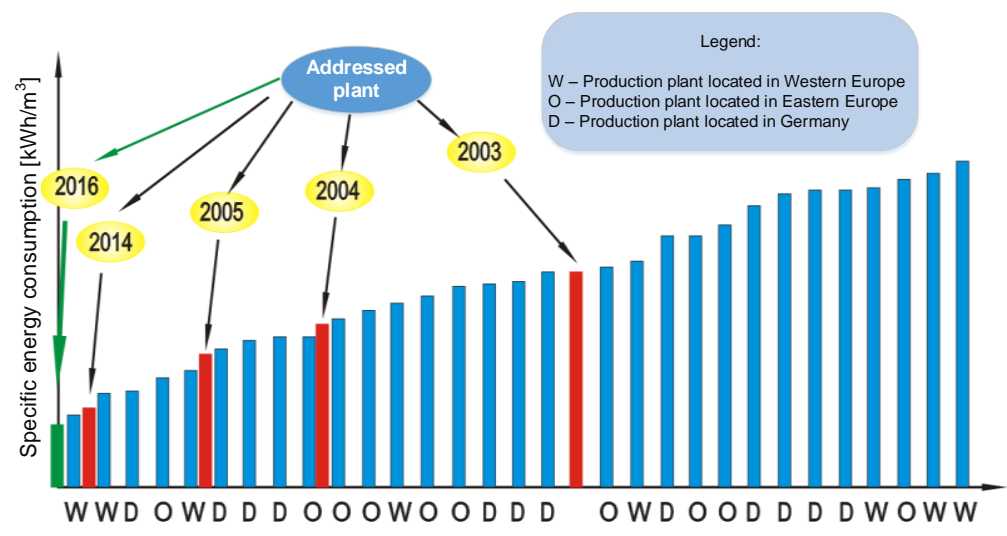

Fig. 2. Evolution of specific energy consumption in addressed plant.

It has to be noted that implemented initial energy efficiency measures motivated company staff to go even further and to look for additional opportunities for improvement of energy and resource efficiency.

\section{Conclusion}

Presented research work confirmed that achievement of measurable energy savings require significant amount of time, efforts and experience and must be supported with the modern monitoring and verification tools. The proposed approach for improving energy efficiency in industrial facilities combined with new metering infrastructure and incorporation of postulates of energy management into routine daily activities represents an introduction of change in people's attitude about energy use. Also, proposed approach is fully in-line with requirements of ISO 50001 especially regarding monitoring relevant variables related to significant energy use. Honest relationship and cooperation between energy manager and his team was very important factor for reaching energy savings. Additionally, practical experiences from energy audit to actual implementation of energy efficiency measures once again confirmed that the successful implementation of energy efficiency projects requires interdisciplinary knowledge and open communication between external experts and energy manager.

\section{References}

1. European Environment Agency, Final energy consumption by sector and fuel (EEA, Copenhagen, Denmark, 2018)

2. H. Klinge Jacobsen, L. L. Pade, S. T. Schröder, L. Kitzing, Renewable Energy 63, 345-352 (2014)

3. P. Garrone, L. Grilli, B. Mrkajic, Energy Policy 109, 49-58 (2017)

4. K. Vikhorev, R. Greenough, N. Brown, J. Cleaner Prod. 43, 103-112 (2013)

5. M. Arens, E. Worrell, Energy 73, 968-977 (2014)

6. M. Pusnik, F. Al-Mansour, B. Sucic, M. Cesen, Energy 136, 52-62 (2017)

7. J.-C. Brunke, M. Johansson, P. Thollander, J. Cleaner Prod. 84, 509-525 (2014) 
8. Directive 2012/27/EU of the European Parliament and of the Council of 25 October 2012 on energy efficiency, amending Directives 2009/125/EC and 2010/30/EU and repealing Directives 2004/8/EC and 2006/32/EC, Official Journal EU L 315 (2012)

9. L. Nabitz, S. Hirzel, Energy Policy 125, 548-561 (2019)

10. Z. K. Morvay, D. D. Gvozdenac, Applied Industrial Energy and Environmental Management (Chichester, John Wiley \& Sons, 2008)

11. R. M. Lazzarin, M. Noro, Appl. Therm. Eng. 90, 509-5205 (2015)

12. J. Petek, P. Glavič, A. Kostevšek, J. Cleaner Prod. 112, 4, 2813-2821 (2016)

13. S. Boldyryev, H. Mikulčić, Z. Mohorović, M. Vujanović, G. Krajačić, N. Duić, Appl. Therm. Eng. 105, 839-848 (2016)

14. F. Friedler, Appl. Therm. Eng. 30, 16, 2270-2280 (2010)

15. J. J. Klemeš, H. L. Lam, Energy 36, 8, 4586-4587 (2011)

16. K. H. Chew, J. J. Klemeš, S. R. Wan Alwi, Z. A. Manan, Appl. Therm. Eng. 61, 1, 17-25 (2013)

17. F. D'Aniello, M. Sorrentino, G. Rizzo, A. Trifirò, F. Bedogni, Appl. Therm. Eng. 137, 277-287 (2018)

18. L. Savulescu, Z. Périn-Levasseur, M. Benali, Appl. Therm. Eng. 61, 1, 143-148 (2013)

19. B. Sucic, P. Lah, B. Petelin Visocnik, J. Cleaner Prod. 142, 4, 3360-3369 (2017)

20. J. Harris, J. Anderson, W. Shafron, Energy Policy 28, 12, 867-876 (2000) 